\title{
Establishment of an experimental model of a Staphylococcus aureus abscess in mice by use of dextran and gelatin microcarriers
}

\author{
C. W. FORD, J. C. HAMEL, D. STAPERT and R. J. YANCEY*
}

Infectious Diseases Research and ${ }^{\bullet}$ Microbiology and Nutrition Research, The Upjohn Company, Kalamazoo, MI 49001, USA

\begin{abstract}
Summary. Staphylococcus aureus $\mathrm{UC}^{\circledR} 9271$ mixed with dextran or gelatin microcarrier beads and injected subcutaneously into mice resulted in the formation of reproducible, sustained abscesses with as few as $2 \times 10^{3} \mathrm{cfu}$. Without microcarrier beads, $4 \times 10^{7}$ cfu were required to produce an abscess. The abscesses that developed with microcarriers attained a diameter of up to $1.5 \mathrm{~cm}$ and persisted for several days before discharging through the skin. The $\mathrm{pH}$ of the abscesses fell from $7 \cdot 1$ to 6.6 within $24 \mathrm{~h}$. Histological and microscopic examination of the abscesses revealed an influx of phagocytic cells, mostly polymorphonuclear leucocytes, within 1-2 $\mathrm{h}$ after injection. Cell debris accumulated and the abscess became encapsulated $24-48 \mathrm{~h}$ after infection. Enzymatic digestion of the abscess contents allowed analysis of the host and bacterial cell populations and treatment with lysostaphin permitted differentiation between phagocytosed and free bacterial populations of $S$. aureus. Phagocytosed but viable $S$. aureus comprised c. $50 \%$ of the total bacterial population after $24 \mathrm{~h}$; however, by $96 \mathrm{~h}$ the phagocytosed population was only $1-5 \%$ of the total population, primarily because of an increase in extracellular bacterial numbers. Prevention of abscess formation by antibiotic treatment based upon the minimal inhibitory concentration (MIC) of an antibiotic for $S$. aureus was not always predictable. Tetracycline did not prevent abscess formation even though it possessed a low MIC for $S$. aureus; methicillin had a borderline MIC value but was quite active. However, the MIC values were quite predictive of antibiotic cures in a systemic-lethal $S$. aureus infection in mice.
\end{abstract}

\section{Introduction}

Abscesses develop as a result of the interaction between invading micro-organisms and host immune defences and represent an interesting therapeutic dilemma because antimicrobial agents are often ineffective (Bartlett et al., 1981; Joiner et al., 1982). Animal models of intraperitoneal and subcutaneous abscesses have proved useful in the study of biological events in the abscess and for the evaluation of antimicrobial agents. Many of these models required that particulate material be injected with the bacteria to trigger abscess development. Alternatively, various artificial pouches, capsules, or even small wiffle balls have been employed within which the bacteria grow (Hays and Mandell, 1974; Simon et al., 1981; Berti et al., 1982; Harris et al., 1984). Abscess-promoting agents used with Escherichia coli and Bacteroides fragilis

Received 7 Jan. 1988; revised version accepted 28 Sep. 1988. have included sterile rodent caecal contents (McConville et al., 1981; Nulsen et al., 1983; Nakatani et al., 1984), disks or microcrystalline forms of cellulose (Actor and Grappel, 1982; Hagen et al., 1983; Fu et al., 1984), and fibrin clots (Wells et al., 1985; Hau et al., 1986). Intraperitoneal abscess models with Staphylococcus aureus have employed several abscess-promoting agents (Lam et al., 1963; Kapral et al., 1980; Hart et al., 1986). Subcutaneous $S$. aureus abscess models have been developed in which the bacteria were injected without promoter (Brook et al., 1983; Rolin et al., 1986) or with mouse caecal contents (Joiner et al., 1980), sutures (Taubler and Kapral, 1966), soft agar (Fujimoto et al., 1986), and particulate mouse feed (Reznikov and McDonald, 1983). While the procedures cited do induce abscess formation in experimental animals, many of the abscesses so formed are too small to permit successful recovery or manipulation of their contents. Those which were large enough to manipulate often used promoting agents which did 
not permit quantitative recovery of bacterial or host cells. We have eliminated these shortcomings through the use of cell-culture microcarriers as abscess-promoting agents in the formation of $S$. aureus subcutaneous abscesses in mice. This system is similar to that described previously with $S$. epidermidis (Ford et al., 1987).

In this report we describe the use of dextran and gelatin microcarriers as abscess promoters in the formation of $S$. aureus subcutaneous abscesses and the effectiveness of antibiotic therapy in preventing abscess formation.

\section{Materials and methods}

\section{Microcarriers}

Cytodex- $1{ }^{\circledR}$ microcarriers (Sigma, St Louis, MO, USA) and Gelibead ${ }^{\circledR}$ microcarriers (K.C. Biological, Lenexa, $\mathrm{KS}$, USA) were prepared according to the manufacturer's instructions. Before use, the supernatant fluid was decanted from the microcarriers that had been allowed to sediment and the beads were pipetted and transferred as a semi-solid gel. Cytodex-1 microcarriers were used in all studies with the exception of growth kinetics studies in which the digestible Gelibead (gelatin) microcarriers were employed.

\section{Bacteria}

Staphylococcus aureus strain $\mathrm{UC}^{\circledR} 9271$, isolated from a subcutaneous abscess, was obtained from $\mathrm{Dr} \mathrm{A}$. Erlandson, Bronson Methodist Hospital, Kalamazoo, MI. The strain was maintained at $-120^{\circ} \mathrm{C}$. Freshly thawed suspensions were diluted in Brain Heart Infusion Broth (BHI; Difco, Detroit, MI) to a density of $2 \times 10^{6}$ $\mathrm{cfu} / \mathrm{ml}$. An equal volume of packed microcarriers was added and this suspension was mixed well. Abscesses were produced by the injection of $0.2 \mathrm{ml}$ of the suspension subcutaneously into CF1 mice (20 gm, male or female; Charles River Labs, Portage, MI).

\section{Enzymes}

The enzyme mixture (Paris et al., 1983) for the dissolution of the gelatin microcarriers in the excised abscesses comprised dispace, trypsin and collagenase. Dispace (Boehringer-Mannheim, St Louis, MO) $40 \mathrm{mg} /$ $\mathrm{ml}$ was dissolved in phosphate-buffered saline (PBS) without calcium and magnesium. Trypsin $6 \mathrm{mg} / \mathrm{ml}$, collagenase $4 \mathrm{mg} / \mathrm{ml}$, and EDTA $4 \mathrm{mg} / \mathrm{ml}$ (Sigma, St Louis, MO) were prepared similarly. Each enzyme solution was divided into $1-\mathrm{ml}$ volumes and stored at $20^{\circ} \mathrm{C}$. Just before use, the enzyme mixture was prepared by combining $1 \mathrm{ml}$ of each thawed enzyme and $6 \mathrm{ml}$ of fresh PBS.

Lysostaphin (Sigma) $100 \mu \mathrm{g} / \mathrm{ml}$ was dissolved in calcium- and magnesium-free Hanks's Balanced Salt Solution (HBSS). The solution was dispensed in 1-ml volumes and kept frozen at $-120^{\circ} \mathrm{C}$. Before use each vial was thawed and diluted with HBSS to give a final concentration of $10 \mu \mathrm{g} / \mathrm{ml}$.

\section{Quantitation of free and phagocytosed S. aureus}

The abscesses from three mice were excised at each time point, placed into a plastic tube containing $1 \mathrm{ml}$ of PBS and $3 \mathrm{ml}$ of enzyme solution was added. After incubation at $35^{\circ} \mathrm{C}$ for $20 \mathrm{~min}$ with gentle mixing, the tubes were centrifuged at $1200 \mathrm{~g}$ for $10 \mathrm{~min}$. The supernate was decanted and the pellet was resuspended in PBS.

Fetal calf serum $10 \% \mathrm{v} / \mathrm{v}$ was added to the supernate and the number of viable $S$. aureus was determined by a plate count. The results were expressed as cfu free $S$. aureus/abscess.

The cell suspension was again centrifuged and resuspended in $3 \mathrm{ml}$ of lysostaphin solution $(10 \mu \mathrm{g} / \mathrm{ml})$. After incubation at $35^{\circ} \mathrm{C}$ for $20 \mathrm{~min}$ the cells were pelleted by centrifugation, washed in HBSS, repelleted, and lysed by resuspension in sterile water. The number of $S$. aureus was assessed by plate count and expressed as the number of phagocytosed $S$. aureus/abscess.

\section{Polymorphonuclear leucocyte content of abscesses}

Polymorphonuclear leucocytes (PMNLs) were quantified microscopically in a haemocytometer. Viable cell counts were done on all suspensions after enzyme treatment of the abscess contents. The results were expressed as PMNLs/abscess.

\section{Antibiotics}

Clindamycin was supplied by The Upjohn Company (Kalamazoo, MI). Penicillin G, methicillin, nafcillin, gentamicin, tetracycline and rifampin were obtained from Sigma. Cefotaxime and vancomycin were purchased as the formulated drugs from local sources. Each antibiotic was prepared fresh each day and was administered subcutaneously (s.c.) immediately after the intraperitoneal injection of bacteria and at 24-h intervals thereafter in the systemic infection model. Alternatively, the antibiotic was administered s.c. on the opposite side of the animal immediately after injection of the loaded microcarriers and $8 \mathrm{~h}$ later. Each drug was administered twice daily for $5 \mathrm{~d}$. On the sixth day the entire abscess contents were plated on to BHI agar and the appearance of any colonies of $S$. aureus was taken to represent persistence of infection. The amount of drug required to cure $50 \%$ of infected animals or eradicate $S$. aureus from $50 \%$ of the abscesses was calculated by probit analysis (Finney, 1978).

\section{Lethal systemic infection model}

CF1 mice weighing $20 \mathrm{~g}$ were obtained from Charles River Laboratories (Portage, MI). The mice were given an intraperitoneal (i.p.) injection of $100 \times$ LD50 of $S$. aureus UC9271 ( $2 \times 10^{7} \mathrm{cfu} /$ mouse) suspended in BHI 
broth containing Brewer's yeast (Sykes et al., 1977) 2\% $\mathrm{w} / \mathrm{v}$. Antibiotic therapy was given as previously. LD50 and curative dose 50 (CD50) determinations with control antibiotics were performed within each test.

\section{Cyclophosphamide treatment}

Cyclophosphamide (Sigma) was administered i.p. to mice in two doses $(200 \mathrm{mg} / \mathrm{kg})$. The second dose was given $2 \mathrm{~d}$ after the first; $2 \mathrm{~d}$ later abscesses were initiated by injection of $S$. aureus-loaded microcarriers.

\section{Determination of abscess $p H$}

Mice were given injections of $2 \times 10^{6} \mathrm{cfu}$ of $S$. aureus mixed with microcarrier beads. Abscess contents were excised at intervals and placed into plastic test tubes which contained $1 \mathrm{ml}$ of distilled water, the $\mathrm{pH}$ of which had been adjusted to $7 \cdot 0$. The abscess contents were dispersed by vigorous pipetting of the suspension. The $\mathrm{pH}$ of the suspension was determined after immersion of the electrode in the suspension with a 10 -min incubation period at room temperature.

\section{Histologic examination of the abscesses}

Excised abscesses and surrounding tissues were fixed by immersion in buffered formalin (Fisher Scientific, Chicago, IL) $10 \%$. These were embedded in paraffin and sectioned. The sections were stained with haematoxylin and eosin (H \& E) and examined by light microscopy.

\section{Results}

\section{The effect of microcarriers on abscess formation}

Microcarriers were essential for establishing a manageable and useful experimental $S$. aureus subcutaneous abscess (table I). Smaller numbers of $S$. aureus were required for successful abscess formation in their presence. When injected alone, S. aureus UC $9271,4 \times 10^{7} \mathrm{cfu}$, produced an abscess which reached a maximal size of $4 \mathrm{~cm}$ and was expressed through the skin. Only small, transient nodules developed at doses of $4 \times 10^{5} \mathrm{cfu}$. With microcarriers, as few as $2 \times 10^{3} \mathrm{cfu}$ of $S$. aureus produced large abscesses, up to $1.5 \mathrm{~cm}$ in diameter. Microcarriers injected alone produced a small and transient lump under the skin. Generally, the fewer bacteria used to induce the abscess, the longer the abscess persisted. For the remainder of the experiments described in this report, abscesses were established with $2 \times 10^{6} \mathrm{cfu}$ of $S$. aureus mixed with microcarriers. Under these conditions the abscesses persisted for 5-7 d before reaching $1.5 \mathrm{~cm}$ and being expressed through the skin.

\section{Quantitation of S. aureus in the abscesses}

Gelatin microcarriers permitted enzymatic digestion of the abscess contents, including the carrier bead (fig. 1). By light microscopy it was determined that the procedure resulted in singlecell suspensions of bacteria and host phagocytic cells. For quantitation of the "free" and "phagocytosed" $S$. aureus, differential centrifugation was used to separate the "free" $S$. aureus from the phagocytic cells, and lysostaphin treatment was then employed to kill those bacteria external to, but associated with, the phagocytic cells. Controls were

Table I. The effect of microcarriers on subcutaneous abscess formation with S. aureus UC9271

\begin{tabular}{|c|c|c|c|c|c|c|c|c|c|c|}
\hline \multirow{2}{*}{$\begin{array}{l}\text { Dose of CFU } \\
\text { of } S \text {. aureus } \\
\text { injected }\end{array}$} & \multirow{2}{*}{$\begin{array}{l}\text { Presence }(+) \text { or absence }(-) \text { of } \\
\text { microcarriers* with the inocu- } \\
\text { lum }\end{array}$} & \multicolumn{9}{|c|}{ Mean abscess score $\dagger$ at post-injection day } \\
\hline & & 1 & 2 & 3 & 4 & 5 & 6 & 7 & 8 & 9 \\
\hline $4 \times 10^{7}$ & - & $2 \cdot 0$ & $2 \cdot 0$ & $3 \cdot 0$ & $3 \cdot 0$ & $4 \cdot 0$ & $\ldots$ & $\ldots$ & $\ldots$ & $\ldots$ \\
\hline $4 \times 10^{6}$ & - & $2 \cdot 0$ & $2 \cdot 0$ & $2 \cdot 0$ & $2 \cdot 0$ & $3 \cdot 0$ & $2 \cdot 7$ & $1 \cdot 0$ & $1 \cdot 0$ & $1 \cdot 0$ \\
\hline $4 \times 10^{5}$ & - & $1 \cdot 0$ & 1.0 & $1 \cdot 0$ & $1 \cdot 0$ & $1 \cdot 0$ & $1 \cdot 0$ & 0 & 0 & 0 \\
\hline $4 \times 10^{4}$ & - & 0 & 0 & 0 & 0 & 0 & 0 & 0 & 0 & 0 \\
\hline $4 \times 10^{3}$ & - & 0 & 0 & 0 & 0 & 0 & 0 & 0 & 0 & 0 \\
\hline $2 \times 10^{7}$ & + & $2 \cdot 0$ & 3.0 & 3.0 & $3 \cdot 5$ & $4 \cdot 0$ & $\ldots$ & $\ldots$ & $\ldots$ & $\ldots$ \\
\hline $2 \times 10^{6}$ & + & $2 \cdot 0$ & 3.0 & 3.0 & $3 \cdot 2$ & $3 \cdot 7$ & $\dddot{4 \cdot 0}$ & $\cdots$ & $\ldots$ & $\ldots$ \\
\hline $2 \times 10^{5}$ & + & $2 \cdot 0$ & 3.0 & 3.0 & 3.0 & $3 \cdot 0$ & 3.0 & $3 \cdot 2$ & $4 \cdot 0$ & $\ldots$ \\
\hline $2 \times 10^{4}$ & + & $2 \cdot 0$ & $2 \cdot 0$ & 3.0 & 3.0 & 3.0 & $3 \cdot 0$ & 3.0 & 3.0 & $\ddot{3.0}$ \\
\hline $2 \times 10^{3}$ & + & $2 \cdot 0$ & $2 \cdot 0$ & 3.0 & 3.0 & $3 \cdot 0$ & 3.0 & 3.0 & 3.0 & 3.0 \\
\hline 0 & + & $1 \cdot 0$ & $1 \cdot 0$ & 0 & 0 & 0 & 0 & 0 & 0 & 0 \\
\hline
\end{tabular}

\footnotetext{
* Cytodex-1 microcarrier beads.
}

$\dagger$ Arithmetic mean of scores, six mice/group. Scores: $0=$ no palpable nodule $; 1=$ barely palpable nodule $; 2=$ nodule $0 \cdot 25-0.5 \mathrm{~cm}$ in diameter $3=$ nodule $>0.5 \mathrm{~cm}$ in diameter $;=$ abscess expressed.

$\ldots=$ abscess previously expressed through the skin. 


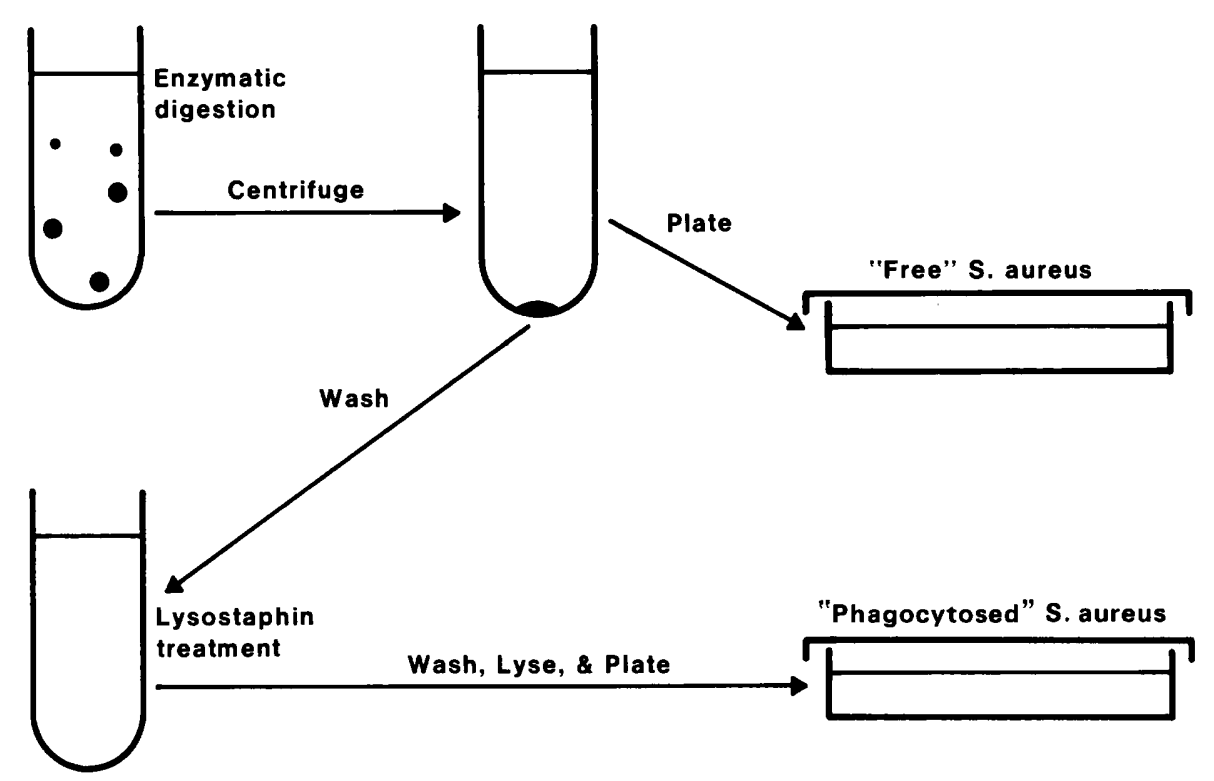

Fig. 1. Procedure for enzymatic digestion and enumeration of free (extracellular) and phagocytosed (intracellular) Staphylococcus aureus.

conducted to ensure that the lysostaphin treatment killed only extracellular bacteria. The "free" $S$. aureus in the supernate after centrifugation were sensitive to lysostaphin. In control experiments, the numbers of extracellular bacteria were reduced from $2 \cdot 3 \times 10^{7}$ to $4.3 \times 10^{3} \mathrm{cfu} / \mathrm{ml}$ with lysostaphin treatment, a survival rate of $0.02 \%$. The $S$. aureus liberated during lysis of the phagocytes became lysostaphin-sensitive proving that they had been intracellular.

\section{Light microscopy of the developing abscesses}

Results of histological examination of the developing abscesses are shown in fig. 2 . Within an hour of injection (fig. $2 \mathrm{a}$ ) the tissue surrounding the site, although distorted, revealed few infiltrative host phagocytic cells. Few microcarrier beads were in evidence; most of them had floated away from the sections during staining, presumably because they were not held in place by a network of host protein and infiltrate cells as they were at later times. A substantial host inflammatory response was evident by $6 \mathrm{~h}$ after injection (fig. 2b). The microcarriers were enmeshed in a matrix of infiltrative cells and the dermis contained appreciable numbers of PMNLs; $24 \mathrm{~h}$ later (fig. 2c), the microcarriers were embedded in a matrix of phagocytic cells, debris, and uniformly staining material which was deposited protein as judged by its staining reaction. The adjacent fat and dermal layers in the skin contained large numbers of host infiltrative cells and were severely distorted. The layer of phagocytic cells and debris surrounding the microcarriers had thickened appreciably by $48 \mathrm{~h}$ following injection (fig. $2 \mathrm{~d}$ ) and thereafter a dark-staining but amorphous band of material was often found between the microcarrier matrix and the phagocytic cell layer. From 72 to $120 \mathrm{~h}$ (data not shown) the abscesses remained much the same microscopically except for the appearance of a layer of protein, the capsule, which enclosed the bulk of the abscess and its contents. The phagocytic cell layer between the capsule and the microcarriers remained thick and laden with debris and was composed principally of PMNLs; $<5 \%$ of the cells appeared to be macrophages and very few lymphocytes were seen. The microcarrier beads remained embedded in a mixture of phagocytic cells, debris, and protein.

Histologic examination of control "abscesses" which were induced with microcarrier beads, but without $S$. aureus, revealed a greatly reduced and transient inflammatory response when compared to the $S$. aureus abscesses. Within $24 \mathrm{~h}$ (fig. 3a), the control fat layer contained scattered infiltrative cells, mostly PMNLs, but very few were observed among the microcarrier beads. No clearly-defined substantial layer of phagocytic cells was found interspersed between the fat layer and the microcarrier beads. In sections from 48 - $h$ controls (fig. $3 b$ ), the microcarrier beads were surrounded by phagocytic cells, but their numbers were dramati- 

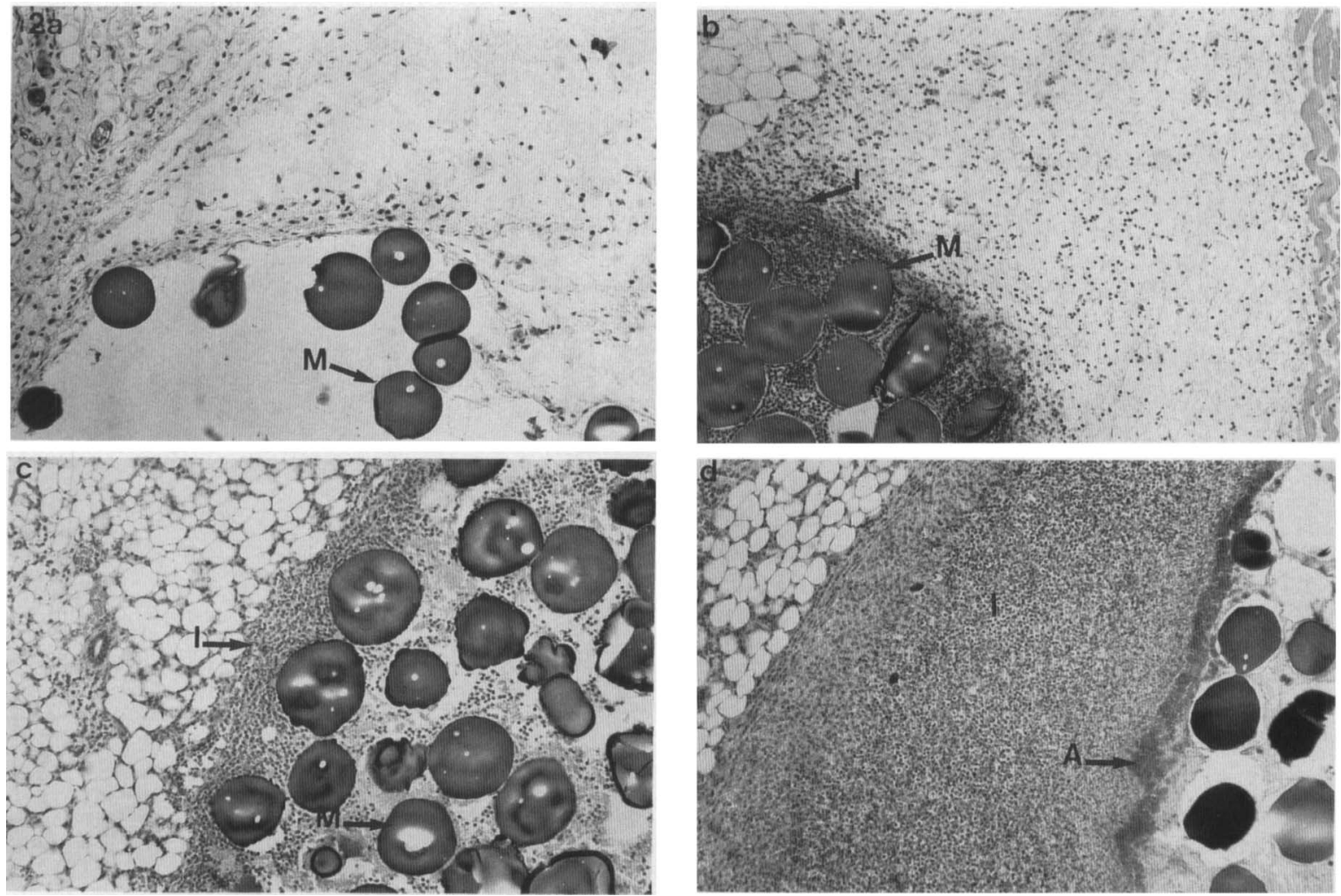

Fig. 2. Histological examination of the Staphylococcus aureus-induced abscess (100×, H \& E stain): a, 1 h; b, 6 h; c, 24 h; d, 48 h. $\mathbf{M}$, microcarrier bead. I, infiltrative host phagocytes. A, amorphous band.
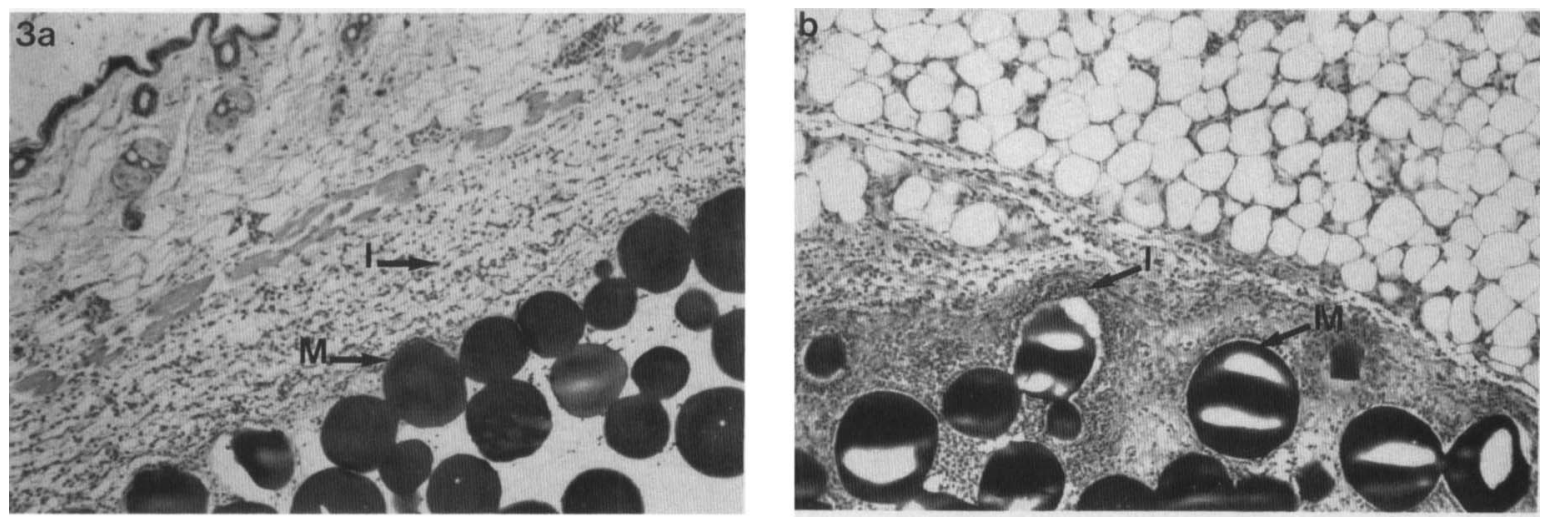

Fig. 3. Histological examınation of microcarrier controls (100×, H \& E stain): a, 24 h, b, 48 h. M, microcarrier bead, I, infiltrative host phagocytes

cally reduced in comparison with abscess sections and the distinct layer of phagocytic cells and debris was noticeably absent. From 48 to $120 \mathrm{~h}$ (data not shown) the numbers of phagocytic cells in controls steadily subsided until by $120 \mathrm{~h}$ the microcarrier beads were suspended in a proteinaceous milieu.

The inflammatory response generated by the injection of microcarrier beads was considerably weaker and of shorter duration than that observed with microcarrier beads and $S$. aureus.

\section{The $\mathrm{pH}$ of the abscess contents}

The $\mathrm{pH}$ of the abscesses measured over a 5 day period, fell substantially. Within the first $24 \mathrm{~h}$ the $\mathrm{pH}$ of the contents of the abscesses fell from $7 \cdot 2$ to 6.7 and, thereafter, remained around 6.6.

\section{Polymorphonuclear leucocyte kinetics}

Measurement of PMNL numbers by light microscopy revealed substantial numbers $\left(3 \times 10^{6} /\right.$ 
abscess) within $2 \mathrm{~h}$ of injection of the abscessforming milieu (fig. 4). Similar numbers of PMNLs were seen at $8 \mathrm{~h}$ but by $24 \mathrm{~h}$ after injection the numbers of PMNLs had risen to about $2 \times 10^{7} /$ abscess. With the exception of a slight decrease in number (at $48 \mathrm{~h}$ ), the numbers of PMNLs remained in excess of $1 \times 10^{7} /$ abscess until the fifth day. As judged by the standard deviation bars, the inflammatory response was highly reproducible from animal to animal.

\section{Kinetics of S. aureus growth}

Growth kinetics of free and phagocytosed $S$. aureus in the abscess was followed (fig. 5) such that within $2 \mathrm{~h} 7 \times 10^{5}$ and $1 \times 10^{5} \mathrm{cfu}$ free and phagocytosed $S$. aureus, respectively, were recovered. By $8 \mathrm{~h}$, both intracellular and extracellular populations had increased to $2 \times 10^{7} \mathrm{cfu} /$ abscess. At $24 \mathrm{~h}$ that number had again increased two-fold. By $48 \mathrm{~h}$ the two bacterial populations began to differ quantitatively. The phagocytosed $S$. aureus gradually declined in numbers from a peak of $4 \times 10^{7} \mathrm{cfu} /$ abscess at $24 \mathrm{~h}$ to $8 \times 10^{6} /$ abscess at $5 \mathrm{~d}$. The numbers of free $S$. aureus increased from $5 \times 10^{7}$ cfu/abscess at $48 \mathrm{~h}$ to $2 \times 10^{8} \mathrm{cfu} /$ abscess at $72 \mathrm{~h}$. The counts of extracellular bacteria stayed essentially the same for the remaining $2 \mathrm{~d}$ : six days after injection these abscesses were expressed through the skin.

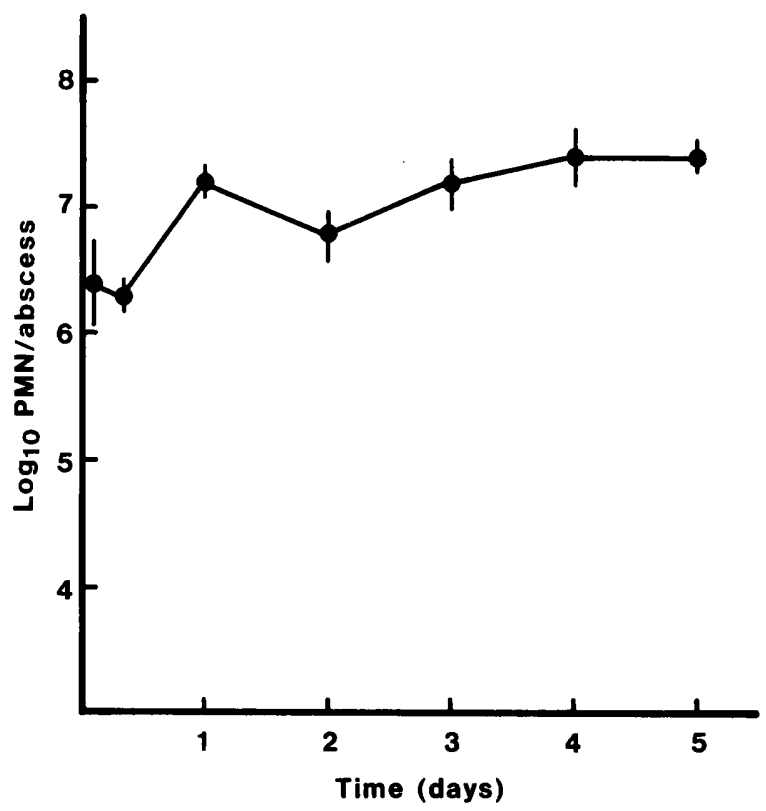

Fig. 4. Quantitation of host phagocytic cell influx into the abscesses. Each point represents the mean value of three determinations (abscesses). $\mathrm{Bar}=\mathrm{SD}$.

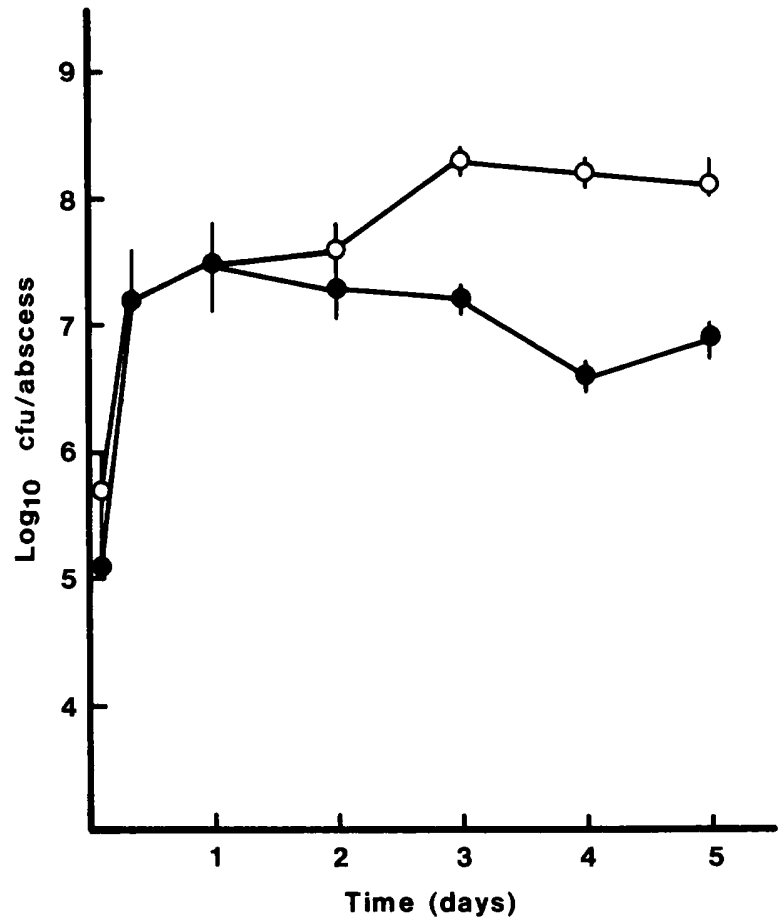

Fig. 5. Number of free (०) and phagocytosed (•) Staphylococcus aureus in the abscess. Each point is the mean of three determinations (abscesses). Bar $=$ SD.

\section{Neutropenia and abscess-associated mortality}

To assess the role of PMNLs in restricting $S$. aureus to the abscess, mice were made neutropenic with cyclophosphamide (Zinner et al., 1981). In preliminary experiments, maximal suppression was obtained $48 \mathrm{~h}$ after the second cyclophosphamide injection. At this time there was a $>90 \%$ reduction in blood neutrophil concentration as determined by microscopic examination. When mice were maximally granulocytopenic at the time of injection of S. aureus, $100 \%$ mortality occurred because of systemic infection with this bacterium. Thus in this abscess model, functioning PMNLs were necessary for $S$. aureus containment and successful development of the abscess.

\section{Antibiotic chemotherapy}

One reason this strain of $S$. aureus was chosen for abscess model development was that it was susceptible to several commercially available antibiotics in vitro (table II). The MIC values obtained generally were predictive of the mean curative doses necessary to treat successfully the systemiclethal infection with this strain. Only nafcillin displayed a much greater mean curative dose than that predicted by its MIC. The MICs were much 
less predictive of the mean protective doses (PD50) needed for therapy of the subcutaneous abscesses. The MIC values of clindamycin, nafcillin, gentamicin, and rifampin were $0 \cdot 12 \mu \mathrm{g} / \mathrm{ml}$ but the PD50 was in the range $0.5-75.0 \mathrm{mg} / \mathrm{kg}$. Tetracycline was relatively ineffective in preventing abscess formation. The PD50's obtained with methicillin and cefotaxime were lower than might have been anticipated from their MIC values and mean curative doses. Penicillin $\mathrm{G}$ was ineffective against this $\beta$-lactamase producing strain. It should be noted that antibiotic therapy was begun at the time of bacterial inoculation in both in-vivo systems. If therapy was delayed by as little as $4 \mathrm{~h}$ while the CD50 values increased only slightly, abscesses could not be treated successfully with any of the antibiotics tested except clindamycin and rifampin (data not shown).

\section{Discussion}

The use of the dextran and gelatin microcarriers was central to the development of this model. Whereas this strain of $S$. aureus alone could induce abscess formation, it did so only at relatively large inoculum sizes $\left(>4 \times 10^{5} \mathrm{cfu}\right)$ and the response was lost upon a ten-fold reduction in inoculum (table I). The inert microcarriers functioned as abscess promoters in that 100 - to 1000 -fold fewer $S$. aureus evoked the same abscess response as $4 \times 10^{7} \mathrm{cfu}$ of $S$. aureus without microcarriers. The use of smaller numbers of $S$. aureus with the microcarriers also prolonged the duration of the abscess.

The relatively gentle method of enzymatic digestion of abscesses formed with gelatin microcarriers

Table II. Comparison of antibiotic activity versus $S$. aureus $\mathrm{UC} 9271$ in vitro and in vivo

\begin{tabular}{l|ccc}
\hline \multicolumn{1}{c|}{ Antibiotic } & MIC $(\mu \mathrm{g} / \mathrm{ml})$ & CD50 $(\mathrm{mg} / \mathrm{kg})$ & PD50 $(\mathrm{mg} / \mathrm{kg})$ \\
\hline Clindamycin & 0.12 & 5.4 & 75.0 \\
Penicillin G & $>8.0$ & $>200.0$ & $>200.0$ \\
Nafcillin & 0.12 & 50.0 & 18.5 \\
Methicillin & 2.0 & 167.6 & 25.0 \\
Cefotaxime & 1.0 & 91.0 & 57.4 \\
Vancomycin & 1.0 & 38.0 & 9.9 \\
Gentamicin & 0.12 & 2.8 & 4.6 \\
Tetracycline & 0.25 & 1.1 & 200.0 \\
Rifampin & 0.06 & 0.05 & 0.5 \\
& & & \\
\hline
\end{tabular}

$\mathrm{MIC}=$ the lowest concentration at which bacterial growth was inhibited in vitro.

$\mathrm{CD} 50=$ the Curative Dose 50, the amount of antibiotic required to cure $50 \%$ of systemically infected animals.

$\mathrm{PD} 50=$ the Protective Dose 50 , the amount of antibiotic required to eradicate $S$. aureus from $50 \%$ of the abscesses when antibiotic dosing was begun at the time of infection. permitted quantitation, separation, and recovery of bacterial and host-cell populations in the abscesses. The analysis of these populations allowed us to characterise the events involved in abscess development. The rapid rate of replication of the $S$. aureus population 2-8 h after infection (fig. 4) was effectively reduced by $24 \mathrm{~h}$, apparently because of the influx of host phagocytic cells (figs. 2 and 4). Consistent with the burst of bacterial replication and the host's phagocytic-cell response was the observed decrease in abscess $\mathrm{pH}$ in the first day and an increase in abscess lysozyme content (data not shown). After $24 \mathrm{~h}$, the numbers of phagocytic cells in the abscesses increased and thereafter remained at constant levels (fig. 4), the abscess $\mathrm{pH}$ stabilised at $6 \cdot 6$, and the escape of bacteria from the abscess site, as indicated by mortality in neutropenic mice (data not shown), decreased dramatically. These observations are consistent with the view that within the first day the host exerted control over the bacterial population(s) at the abscess site, primarily through the influx and activity of phagocytic cells. In addition, microscopic examination led us to believe that by $1-2 \mathrm{~d}$ all of the structural abscess elements, i.e., capsule, were present at the abscess site.

The numbers of phagocytosed $S$. aureus reached a peak at $24 \mathrm{~h}$ and then decreased somewhat (fig. $5)$. In sharp contrast, the numbers of free $S$. aureus increased substantially from $2-3 \mathrm{~d}$ and then remained relatively constant. The observed divergence in actual numbers of free and phagocytosed $S$. aureus was consistent over the course of several experiments. This increase in free $S$. aureus may represent a loss of host phagocytic control over bacterial replication. As evidenced by the plateau in numbers of free $S$. aureus (fig. 5), the host, from $3 \mathrm{~d}$ onwards, effectively exerts control over the bacteria in the abscess. The second phase of control over bacterial replication is probably achieved by the abscess structure itself; the abscess is walled-off by the capsule. The bacteria are trapped within and may be nutritionally deprived. This experimental abscess presents an interesting sequence in which the host initially limits bacterial spread and replication by the action of phagocytic cells and follows this with structural containment of the bacteria.

The consistent increase in free $S$. aureus at 2-3 d after infection, was not seen with $S$. epidermidis (Ford et al., 1987) or E. coli (data not shown) in subcutaneous abscess models with these organisms. We have also observed that the $S$. epidermidis and $E$. coli abscesses are less intense than the $S$. aureus abscesses, as judged by histological observation of 
inflammation and cell debris. The host may be better able to control the absolute numbers of free bacteria in these abscesses.

With the exception of tetracycline, antibiotics which were effective in the treatment of the systemic infection were also capable of effecting microbiological cures of the abscesses (table II) when the first treatment was administered immediately following injection of the abscess-forming milieu. Penicillin,

\section{REFERENCES}

Actor P, Grappel S F 1982 Efficacy of ceftizoxime and related compounds in animal models of infection. Journal of Antimicrobial Chemotherapy 10 Suppl. C. : 81-89.

Bartlett J G, Louie T J, Gorbach S L, Onderdonk A B 1981 Therapeutic efficacy of 29 antimicrobial regimens in experimental intra-abdominal sepsis. Reviews of Infectious Diseases 3: 535-542.

Berti M, Rossie E, Candiani G, Arioli V 1982 A new model of experimental Bacteroides fragilis infection in mice and rats. Chemotherapy 28: 213-217.

Brook I, Coolbaugh J C, Walker R I 1983 Antibiotic and clavulanic acid treatment of subcutaneous abscesses caused by Bacteroides fragilis alone or in combination with aerobic bacteria. Journal of Infectious Diseases 148: 156-159.

Finney D J 1978 Statistical method in biological assay, 3rd edn., Charles Griffin \& Co. Ltd, London.

Ford C W, Hamel J C, Stapert D, Yancey R J 1987 Antibiotic therapy for an experimental Staphylococcus epidermidis subcutaneous abscess in mice. Zentralblatt für Bakteriologie, Mikrobiologie und Hygiene Suppl 16: 247-257.

Fu K P, Lasinski E R, Zogonas H C, Kimble E F, Konopka E A 1984 Therapeutic efficacy and pharmacokinetic properties of rifampicin in a Bacteroides fragilis intraabdominal abscess. Journal of Antimicrobial Chemotherapy 14: 633-640.

Fujimoto T et al. 1986 Chemotherapeutic efficacy of ofloxacin on renal and subcutaneous infection models with Staphylococcus aureus in mice. Chemotherapy 32 : 291-298.

Hagen J C, Wood W S, Hashimoto T 1983 Experimental intraabdominal abscess formation by Escherichia coli and Bacteroides fragilis. European Journal of Clinical Microbiology 2: 43-49.

Harris R W, Moore W L, Arensman J B, Rissing J P 1984 Antimicrobial activity of latamoxef (moxalactam) against both Bacteroides fragilis and Escherichia coli in an intraperitoneal abscess model. Journal of Antimicrobial Chemotherapy $14: 499-508$.

Hart P H, Spencer L K, Nulsen M F, McDonald P J, FinlayJones J J 1986 Neutrophil activity in abscess-bearing mice: comparative studies with neutrophils isolated from peripheral blood, elicited peritoneal exudates, and abscesses. Infection and Immunity 51 : 936-941.

Hau T, Jacobs D E, Hawkins N L 1986 Antibiotics fail to prevent abscess formation secondary to bacteria trapped in fibrin clots. Archives of Surgery 121: 163-168.

Hays R C, Mandell G L $1974 \mathrm{PO}_{2}, \mathrm{pH}$, and redox potential of experimental abscesses. Proceedings of the Society for Experimental Biology and Medicine 147: 29-30.

Joiner K, Lowe B, Dzink J, Bartlett J G 1982 Comparative efficacy of 10 antimicrobial agents in experimental infections with Bacteroides fragilis. Journal of Infectious Diseases 145: $561-568$. which had an MIC indicating it was ineffective against the $S$. aureus strain, cured neither the systemic-lethal infection nor the abscess. Even though other antibiotics were effective in preventing abscess formation, their PD50 values were not directly proportional to the CD50 values. Antibiotic effectiveness, as judged by MICs and treatment of systemic infection, was not predictive of antibiotic performance against the developing abscesses.

Joiner K A, Onderdonk A B, Gelfand J A, Bartlett J G, Gorbach S L 1980 A quantitative model for subcutaneous abscess formation in mice. British Journal of Experimental Pathology 61: 97-107.

Kapral F A, Godwin J R, Dye E S 1980 Formation of intraperitoneal abscesses by Staphylococcus aureus. Infection and Immunity 30: 204-211.

Lam G T, Sweeney F R, Witmer C M, Wise R I 1963 Abscessforming factor(s) produced by Staphylococcus aureus I. Collodion bag implantation technique. Journal of Bacteriology 86: 611-615.

McConville J H, Snyder M J, Calia F M, Hornick R B 1981 Model of intra-abdominal abscess in mice. Infection and Immunity 31 : 507-509.

Nakatani T, Sato T, Manzella L, Hirai F, Trump B F, Siegel J $\mathrm{H} 1984$ Hepatic and systemic metabolic responses to aerobic and anaerobic intra-abdominal abscesses in a highly reproducible chronic rat model. Circulatory Shock 13: 271294.

Nulsen M F, Finlay-Jones J J, Skinner J M, McDonald P J 1983 Intra-abdominal abscess formation in mice: quantitative studies on bacteria and abscess-potentiating agents. British Journal of Experimental Pathology 64: 345-353.

Paris M S, Eaton D L, Sempolinski D E, Sharma P B 1983 A gelatin microcarrier for cell culture. 35th Annual Meeting of the Tissue Culture Association, Orlando, FL.

Reznikov M, McDonald P J 1983 Effect of metronidazole on Escherichia coli in the presence of Bacteroides fragilis: an investigation in mice. Chemotherapy 29: 225-229.

Rolin O, Huet Y, Bouanchaud D H 1986 Comparative efficacy of pefloxacin and six other antimicrobial agents on Staphylococcus aureus experimental abscesses. Journal of Antimicrobial Chemotherapy 17 Suppl B: 49-52.

Simon G L, Richmond D M, Tally F P, Barza M, Gorbach S L 1981 Penetration of clindamycin into experimental infections with Bacteroides fragilis. Journal of Antimicrobial Chemotherapy 8: 59-64.

Sykes R B, Griffiths A, Ryan D M 1977 Comparative activity of ampicillin and cefuroxime against three types of Haemophilus influenzae. Antimicrobial Agents and Chemotherapy 114: 599-604.

Taubler J H, Kapral F A 1966 Staphylococcal population changes in experimentally infected mice: infection with suture-adsorbed and unadsorbed organisms grown in vitro and in vivo. Journal of Infectious Diseases 116: 257-262.

Wells C L, Arland L A, Simmons R L, Rotstein O D 1985 Invivo bactericidal activity of Sch 34343 in Bacteroides fragilis abscesses and in Bacteroides fragilis-Escherichia coli abscesses. Journal of Antimicrobial Chemotherapy 15 Suppl C: 199-206.

Zinner S H, Klastersky J, Gaya H, Bernard C, Ryff J C 1981 Invitro and in-vivo studies of three antibiotic combinations against gram-negative bacteria and Staphylococcus aureus. Antimicrobial Agents and Chemotherapy 20: 463-469. 